\title{
HOLOPRAXIS NA ENFERMAGEM: Dificuldades, experiências e possibilidades ${ }^{1}$ \\ HOLOPRAXIS IN NURSING: DIFFICULTIES, EXPERIMENTS AND POSSIBILITIES.
}

Irani Aparecida Dalla Costa Paes ${ }^{2}$

RESUMO: Este trabalho tem por finalidade buscar possibilidades de avanços na enfermagem, através das holopraxis íntima, cotidiana e social. Acreditamos que as holopraxis favorecem uma melhor visualização do processo saúde-doença e, conseqüentemente, resulta numa melhora da qualidade da prestação de cuidados e propicia a superação parcial ou tołal das dificuldades encontradas no exercício da enfermagem.

UNITERMOS: Enfermagem - Holopraxis - Processo saúde-doença.

ABSTRACT: This work aims at seeking possibilities of advances in Nursing through intimate, daily and social holopraxis. We believe that holopraxis favors a better view of health / illness process and, consequently, it results in upgrading health care delivery quality, allowing partial or total difficulties overcome in Nursing exercise.

KEYWORDS: Nursing - Holopraxis - Health / illness process.

\section{INTRODUÇÃO}

As holopraxis, segundo Pierre Weil24, correspondem às práticas que propiciam ao ser humano alcançar uma vivência holística, a qual torna possivel uma visão holística do mundo (natureza e ser humano).

Nesta visão, o todo e as partes formam um conjunto interdependente, interligado, complementar e em constante movimento (evolução). O "eu" é integrado no todo (mundo social) com suas partes (interior da própria pessoa). Neste trabalho temos a enfermagem como "eu", procurando meios que

${ }^{1}$ Este trabalho é parte da dissertação para a obtenção do Título de Mestre em Educação, pela UNIMEP.

${ }^{2}$ Mestre em Educação, pela UNIMEP; Professora de Enfermagem em Pediatria e Neonatologia e Enfermagem em Doenças Transmissiveis, pela Fundação Hermínio Ometto. 
possibilitem a sua integração com o todo (sistemas maiores e menores). Acreditamos que através das holopraxis (social, cotidiana e intima) alcançaremos nosso objetivo.

Para melhor compreensão, precisamos entender: enfermagem, processo saúde-doença e holopraxis.

A enfermagem, como profissão, para George "et al"11 "tem como responsabilidade a prestação de auxílio a pessoas, grupos, famílias e comunidades, de modo que eles conservem, consigam e mantenham-se em estado de saúde".

A saúde, em termos holísticos, segundo Fritjof Capra ${ }^{5}$ é baseada na concepção sistêmica de vida ${ }^{3}$. Para uma pessoa ser saudável é preciso manter um certo grau de estabilidade, dentro dos limites obtidos através das "flutuações contínuas, múltiplas e interdependentes" do mundo social, cotidiano e pessoal. A doença passa a ser vista como uma desestabilidade dessas flutuações. Passamos a ver saúde e doença como um processo contínuo e complexo, vinculado ao meio social, cultural e econômico.

Segundo Silva et al ${ }^{21}$, a subjetividade e complexidade do processo saúdedoença se devem aos seguintes pressupostos: são antagônicos e complementares ao mesmo tempo, portanto indissociáveis, fazendo parte de um processo único; são expressões sociais e individuais formando uma totalidade, evidenciando o constante conflito social, ultrapassando a noção linear de causaefeito, em que a objetividade deve refletir-se sobre a evolução das relações num determinado momento e numa determinada realidade social. A subjetividade é a expressão desses significados objetivos, através da conscientização. "O homem como ser prático e consciente, integrado ao processo histórico de uma totalidade social mais ampla, tem potencial de ação e de transformação sobre esta sociedade e, portanto, sobre o processo saúde-doença".

A enfermagem, por fazer parte da vida social, também é responsável pela transformação e ação sobre o processo saúde-doença e para que tenhamos bons resultados precisamos acreditar em mudanças.

Pierre Weil considera dois enfoques como essenciais para se atingir uma visão holística integral da realidade: o primeiro, a holologia, consiste no saber, na "obtenção ou desenvolvimento de uma compreensão clara e de uma interpretação correta da não-dualidade, pelos meios clássicos, ligados ao pensamento discursivo" 9 . É a maneira pela qual acredita ser possivel ver o mundo como um todo. O segundo enfoque, as holopraxis, referem-se ao ser, abrangendo os métodos práticos que permitem uma vivência holística ou transpessoal.

Weil distingue três tipos de holopraxis: uma aplicada à sociedade, outra à vida cotidiana e, por último, à vida íntima.

${ }^{3}$ Os sistemas são totalidades integradas como uma teia de interconexões, em que as partes compõem o todo e o todo entrelaçado pelas partes torna-se único ${ }^{10}$. 
A holopraxis social é aquela que abrange instituições e entidades de qualquer origem, que tenham como finalidade "construir pontes sobre todas as fronteiras: internacionais, religiosas, culturais, profissionais e políticas" 2 . Por ser uma prática abrangente e dependente de pessoas que nem sempre possuem um aguçado espírito inovador ou renovador, torna-se pouco utilizável, pela dificuldade em se atingir o cerne da desavença.

A holopraxis da vida cotidiana é obtida pela tradição, pelos valores e sentimentos de bondade, de alegria e de amor que o ser humano presta a si mesmo, profissional ou socialmente, "através de uma vida harmoniosa, com abertura generosa, prática dos valores éticos, paciência, perseverança, atenção, discernimento, amor altruísta, ajuda aos necessitados, alegria de viver e dar felicidade aos outros e espírito equânime" ${ }^{2}$, em qualquer situação que se encontrar. Essa prática é mais fácil de ser aplicada, pois dependerá exclusivamente da pessoa, do seu "eu interior" relacionado com o seu mundo exterior.

A holopraxis intima é a prática de meios que levam a uma vivência transpessoal. Utilizam-se técnicas que proporcionam ao individuo ultrapassar os limites do ego e retornar ao Ser. É a busca do "eu interior", da união do consciente e do inconsciente, da mente e do corpo, da matéria e do espírito, do pensamento e da emoção, da consciência individual e cósmica, pois somente assim conseguiremos atingir algo mais do que nós mesmos, para finalmente estarmos aptos a aplicar esse conhecimento à holopraxis da vida cotidiana e, quem sabe, à social.

Acredito ser difícil almejar o universo (social - mundo) sem antes conhecer o meu próprio universo (o eu).

Uma vez que as pessoas consigam compreender e utilizar as holopraxis, poderão, então, segundo Weil, entender o significado da visão holística em vários ramos profissionais.

A escolha do termo holopraxis neste trabalho deve-se à afinidade do seu significado com a prática de enfermagem.

\section{METODOLOGIA}

O enfoque foi teórico-reflexivo sob fontes secundárias. Este trabalho representa uma necessidade pessoal de conhecer e aprofundar-se sobre questões como a enfermagem e a visão holística.

Devemos ressaltar, neste instante, a importância da fundamentação científica para essa visão. Para conseguirmos entendê-la, buscamos o conhecimento, inicialmente, na física e na biologia moderna.

A física, com a teoria da relatividade, a teoria quântica, o modelo quânticorelativístico, a mecânica-quântica e a holografia, propiciou, segundo Heisenberg apud Capra", um novo enfoque em que "o mundo aparece como um complicado 
tecido de eventos, no qual conexões de diferentes tipos se alternam ou se sobrepõem ou se combinam e, dessa maneira, determinam a textura do todo" (essas conexões são entrelaçadas como uma presilha de botas - hipótese "bootstrap"). Apesar dessas teorias não serem satisfatórias para explicar de maneira convincente a presença dos corpos macroscópicos, abriu-nos novas perspectivas de vida, relacionadas com o mundo subatômico e estelar.

A biologia, com a teoria dos sistemas do ser vivo (auto-organização) e sua capacidade de auto-manutenção (homeocinética) com outros sistemas maiores ou menores, mantidos através de um estado de contínua flutuação, permite uma adaptação do mundo interno com o externo. Aqui também ocorre um entrelaçamento entre sistemas.

Podemos então erigir uma hipótese de que tanto a física moderna quanto a biologia de sistemas servem como suportes para o pressuposto da visão holística, quando dizem que o todo está nas partes e as partes estão no todo, assim como as holopraxis, que procuram meios para se alcançar a integração do ser humano consigo mesmo e com os sistemas externos.

$\mathrm{Na}$ enfermagem enfocaremos, entre tantas, quatro teorias que trabalham dentro desta visão: Transcultural, de Leininger; Transpessoal, de Watson; Autocuidado, de Orem; e Sistemas Abertos e Consecução de metas, de King.

A Teoria Transpessoal de Cuidar/Cuidado, de Jean Watson, evidencia o cuidado, o cuidar e a necessidade da co-participação enfermeira-cliente, para o controle, conhecimento e promoção de mudanças na saúde, que só ocorrerão quando existirem fatores indispensáveis para a estruturação do cuidado: fé e esperança; sistema de valores humanos e altruístas; sensibilidade ao próprio "self" e aos das demais pessoas; relacionamento de ajuda-confiança; promoção e aceitação da expressão de sentimentos positivos e negativos; tomada de decisões frente aos problemas; ensino-aprendizagem interpessoal; ambiente de apoio, proteção e/ou ajuda mental, física, social, cultural e espiritual; atendimento às necessidades humanas e admissão de forças existenciais.

A Teoria do Autocuidado, de Dorothea E. Orem, acredita que a enfermagem tem como preocupação especial "a necessidade de ações de autocuidado do indivíduo, e o oferecimento e controle disso, numa base contínua para sustentar a vida e a saúde, recuperar-se de doença ou ferimento e compatilizar-se com se us efeitos" ${ }^{11}$.

A Teoria dos Sistemas Abertos, de Imogene M. King, defende que os seres humanos são formados por três sistemas interativos: os pessoais, compreendidos pela interação do indivíduo com o meio ambiente; os interpessoais, formados pela composição de pequenos ou grandes grupos interrelacionados entre si; e os sociais, contendo a união de interesses e necessidades comuns de grupos formando comunidades e sociedades. A Teoria de Consecução de Metas é prevista principalmente no sistema interpessoal, que permite o encontro entre duas pessoas estranhas, numa organização de atendimento à saúde, ocorrendo a troca ou o auxílio para a manutenção do estado de saúde de um indivíduo ou grupos. 
Essas teorias, a meu ver, apesar das diversidades, possuem uma única $r$ sta: o cuidar/cuidado holístico em enfermagem. Podemos relacioná-las com a 7 :oria Geral dos Sistemas, da Biologia, em que o ser humano é parte integrante $€$ ativa de um sistema maior que o influencia e é influenciado por ele, através da ti ica de informações "Feedback" ciclicas, bem como com a Hipótese "i sotstrap", da Física, em que a enfermagem interage com o cliente, como uma p zsilha de bota, sendo ambos considerados importantes e igualmente capazes $r_{\text {i }}$ s tomadas de decisões.

\section{DIIICULDADES EXISTENTES NA ENFERMAGEM, QUE ESTORVAM A UTILIZAÇÃO DAS HOLOPRAXIS}

No cotidiano da enfermagem existem situações em que podemos observar dificuldades enfrentadas pelo profissional Enfermeiro, ao tentar desenvolver um trabalho eficiente e de qualidade.

Relataremos, como exemplo, três situações concernentes às atividades dos enfermeiros em campo de trabalho, que mostram uma determinada realidade profissional e depois extrairemos as dificuldades que as cerceiam.

Situação 1: A enfermeira com cargo de chefia de enfermagem num hospital geral de médio porte geralmente conta com um número elevado de atendentes de enfermagem e poucos auxiliares, técnicos e enfermeiros, sendo que muitas vezes há somente atendentes, acarretando deficiência no atendimento, tanto em nível assistencial (prático - cuidado direto) quanto administrativo (organizacional). Além do problema da mão-de-obra, também podemos encontrar déficit na planta física da instituição, comprometendo ainda mais a qualidade do cuidado de enfermagem. Em outros casos, as instituições não oferecem materiais e equipamentos mínimos para um bom funcionamento, sendo que às vezes encontramos essas deficiências simultaneamente.

Situação 2: Enfermeira trabalhando num hospital de médio porte, com materiais e equipamentos de boa qualidade e atuais, estrutura física adequada e número suficiente de enfermeiros, técnicos e auxiliares de enfermagem, e raros atendentes. Sua atuação, porém, é restrita, pois há submissão ao sistema e aos médicos, deixando prevalecer em geral as técnicas de enfermagem baseadas na prescrição médica, cumprindo horários, sem questionar o por quê ou para quê, como se fosse um robô, pronto para cumprir ordens. Nesse caso, a enfermeira conta com todos os recursos, mas não encontra espaço como profissional.

Situação 3: Enfermeiro trabalhando num posto de saúde da rede pública municipal: apesar do profissional ser preparado, no curso de graduação, para entender seu papel na atuação junto à comunidade e ao cidadão, promovendo o atendimento primário, ou melhor, preventivo, em relação à saúde, na realidade, sua função está ligada à política administrativa local, dirigida indiretamente pelo Estado. É este que delimita as metas para o serviço de saúde. Especificamente nesse caso, o enfermeiro fica subordinado às regras (jogo político), encontrando 
problemas do tipo: sabendo que foi detectada contaminação de água num determinado bairro (pobre) da cidade, motivando problemas gastrintestinais à população, ele encaminha um pedido para a administração local pesquisar e sanar esse problema, ocorrendo que muitas vezes o pedido fica arquivado até que os responsáveis resolvam discutir e solucionar, de acordo com as conveniências políticas do momento. O profissional fica sem resposta, ou melhor, soluções, tornando-se insatisfeito com seu trabalho, mas raramente insistindo para a resolução do caso, acomodando-se dizendo que o problema não é mais seu.

Como esses exemplos, provavelmente existirão outros, mas de maneira direta ou indireta. Nas explanações acima podemos verificar algumas das dificuldades existentes, que estorvam a atuação da enfermagem no processo saúde-doença do ser humano. Dividiremos essas dificuldades em fatores extrínsecos e intrínsecos à enfermagem.

\section{Fatores extrinsecos à enfermagem que interferem no trabalho do enfermeiro}

\section{- A fragmentação e a sua influência na saúde}

O reducionismo e a fragmentação provocados pela ciência de Descartes e Newton promoveram um mergulho nas profundezas das partes, iniciando uma procura cada vez mais incessante das causas e efeitos que pudessem justificar as doenças e/ou defeitos apresentados pelo corpo humano. A resultante na área da saúde foi a fragmentação do ser humano em partes, propiciando a formação intensiva de especialistas. E esses especialistas, hoje, tratam as partes, não conseguindo mais cuidar do homem como um todo, integrando essas partes. A enfermagem, por seguir os preceitos da medicina, conseqüentemente está evoluindo para as especializações. Não estamos dizendo que é errado ser um especialista e sim para que os especialistas acordem e voltem a visualizar o ser humano como um todo integrado a um meio.

\section{- Ênfase na etiologia das doenças}

Com a necessidade de buscar respostas para as doenças, os cientistas, de acordo com suas descobertas, propuseram duas principais causas: a primeira está relacionada à ênfașe nas necessidades fisiológicas, envolvendo causas e efeitos sobre o funcionamento das partes do corpo (nesse momento ingressam no mundo fantástico da cirurgia reparadora). A segunda está relacionada aos micróbios (a partir de Pasteur e Koch); surge então a idéia de que as bactérias são as causas subjacentes das doenças, levando à procura de agentes que poderiam destruir os micróbios. Esse novo enfoque, provedor de doenças, levou à formação de um número elevado de cirurgiões (aumentado o número de cirurgias desnecessárias); à redução, no mercado, de clínicos gerais (devido à desvalorização desse profissional); e ao desenvolvimento da indústria farmacêutica conduzindo ao uso de remédios como fonte de salvação das doenças. A saúde deixa de ser o alvo e a doença torna-se o novo enfoque da área de saúde. 


\section{- Os remédios como fonte de cura}

Com certeza a eficiência e a ação dos remédios sobre as causas e efeitos do funcionamento do organismo são evidentes. Mas o problema é que esses benefícios em geral propiciaram o uso abusivo tanto pela medicina quanto pela própria pessoa, induzida pelas propagandas fantásticas produzidas pelas indústrias farmacêuticas. $O$ fato é que esses benefícios vivem lado a lado com os efeitos colaterais, que muitas vezes são nocivos à saúde. Queremos mostrar que os remédios enfatizam a doença e não a saúde propriamente dita.

\section{- A tecnologia avançada e o seu emprego na saúde}

A tecnologia é um grande avanço na área médica; na verdade aqui questionamos a inacessibilidade para a maioria da população; os riscos gerados por ela; e uso pelos médicos, muitas vezes sem necessidade. Quando a alta tecnologia (tomografia computadorizada, cintilografia e outros) é necessária como exame complementar de diagnóstico, deverá ser utilizada, mas o que ocorre é que muitas vezes, para se ter acesso à ela as pessoas entram em filas ou pagam por esse serviço especializado, geralmente centralizado nos grandes centros urbanos.

\section{- A dominação da classe médica na saúde}

A própria sociedade emitiu aos médicos o alvará de mediadores entre saúde e doença, permitindo que eles fossem os responsáveis para determinar quem está ou não doente e quais as medidas que devem ser tomadas face a esta ou aquela situação (autonomia profissional). Os enfoques de trabalho da medicina são: doença; contexto biológico do corpo (reducionismo); comando e chefias em instituições de saúde; especializações e subespecializações; e a morte descaracterizada (deixa de ser um processo natural e passa a ser vista como um fracasso profissional). Esses enfoques propiciaram o fortalecimento sócioeconômico da categoria e a manutenção do "status", oferecidos pela credibilidade técnica, levando a uma soberania sobre outras profissões da área da saúde; com isso gerou-se uma dependência dos outros profissionais e do próprio sistema à medicina.

\section{- A saúde e a doença como produtos comercializáveis}

Hoje o que notamos é instituições de saúde cada vez mais especializadas em vender saúde, promover doença e manter o "status" da elite médica, através das especialidades e das tecnologias sofisticadas. Na verdade a deficiência do sistema de saúde pública foi a prerrogativa para que a classe médica, como solução desse impasse, oferecesse os famosos convênios para empresas e pessoas civis. Em parte, até que resolveram os problemas, mas a maioria dos convênios não cobrem todas as despesas (as que geralmente tem custo alto). Mais uma vez notamos a centralização do poder perante outras áreas da saúde. 


\section{- A deteriorização das condições básicas de vida}

Para nossa sobrevivência necessitamos de condições básicas como: alimentação adequada; moradia; emprego salubre; saneamento de água e esgoto; coleta e destino apropriado do lixo; educação; lazer; sono; higiene pessoal e ambiental; preservação do meio ambiente; segurança; afeto; fé; sexo; vestuário; saúde e outras. Mas nem sempre na nossa realidade são oferecidas essas condições ideais; portanto é favorecido o aparecimento de doenças, com conseqüentemente necessidade de tratamentos e acompanhamentos especializados.

\section{Fatores intrínsecos à enfermagem que interferem no trabalho do enfermeiro}

\section{- Mão de obra pouco qualificada}

A mão-de-obra geralmente é pouco qualificada, devido a pessoas que trabalham sem nenhum conhecimento técnico na área de enfermagem (atendentes); um número elevado de profissionais serem de formação escolar de nivel médio (enfatiza-se a técnica e não a assistência integral); falta de incentivo pelas instituições e chefias para atualizações em determinados ramos e, também, por falta de estruturas (física ou de materiais, equipamentos); más condições de trabalho nas instituições de saúde; escassez de mão-de-obra relativa à baixa remuneração e reconhecimento profissional.

\section{- Discriminação devido à prevalência do sexo feminino na profissão}

$\mathrm{Na}$ realidade o fator "sexo" não é exclusividade da enfermagem, pois a mulher em todos os campos ou áreas sofre a discriminação social em relação ao homem. Salários e atividades para a mulher geralmente são oferecidos em niveis inferiores. E a agravante na enfermagem é ser uma profissão predominantemente feminina. Enquanto houver submissão, desvalorização, marginalização e despolitização da mulher, a enfermagem continuará frágil e doente perante o mundo real.

\section{- Submissão ao sistema de saúde e aos médicos}

A falta de autonomia profissional basicamente se deve à profissão ter emergido de práticas empíricas sem embasamento teórico; às primeiras escolas de enfermagem se orientarem pelos preceitos da medicina; vínculos empregatícios com instituições precárias, com jornadas de trabalho intensa, baixa remuneração financeira e excessiva responsabilidade legal, além da própria responsabilidade do profissional, que opta por empregos com vínculo institucional, por acomodação ou melhor conveniência pessoal, aceitando com isso as regras das instituições. 


\section{- Desunião das categorias de enfermagem}

É complicado tratar desse tópico, pois muitas vezes o enfermeiro aproveita essa ocasião para mostrar a sua autonomia, quer dizer, manter o seu "status" enquanto profissional. Outro fato é a desvinculação da teoria com a prática (os técnicos e auxiliares ficam com a prática e o enfermeiro com a teoria) que, mais uma vez, dificulta a relação entre as categorias da enfermagem.

\section{- Pouco incentivo à pesquisa na área}

Relacionamos, juntamente com outros autores ${ }^{6,7,17}$, as dificuldades que o enfermeiro encontra para realizar uma pesquisa: o despreparo do profissional na metodologia científica; afastamento de atividades em instituições de ensino; falta de incentivo por parte das administrações e das chefias do serviço de enfermagem; sobrecarga de trabalho e de jornada de trabalho; falta de colaboração dos próprios colegas; falta do hábito de ler e de escrever; acesso difícil às fontes; divulgação deficitária; pouca aplicação do conhecimento adquirido na prática; falta de intercâmbio cultural; ausência de espaço e tempo para estudar; insegurança em proceder a pesquisa e resistência às mudanças. Podemos notar que esses obstáculos impedem o crescimento da enfermagem enquanto profissão reconhecida.

\section{- Perfil e papel do enfermeiro}

O perfil está direcionado à prevalência do sexo feminino; procura por pessoas desqualificadas (prostitutas, bêbadas); domínio que o enfermeiro exerce sobre as categorias de enfermagem e os clientes; desunião entre as categorias; concorrência entre a enfermeira e o médico (domínio dos conhecimentos científicos); centralização da mão-de-obra em hospitais (na área curativa); e inércia política e social do enfermeiro. O papel do enfermeiro se dirige para áreas: assistencial, administrativa e educativa (a pesquisa não é prioridade na enfermagem), sendo que muitas vezes o enfermeiro prefere assumir a função administrativa. Quando solicitado, executa a função educativa, transferindo a assistencial para o auxiliar ou técnico ou atendente de enfermagem, revigorando um perfil e papel que nem sempre é reconhecido e admirado por outros profissionais e clientes.

Observamos que muitas dessas dificuldades são inerentes ao contexto sóciopolítico-econômico-cultural de uma determinada sociedade, o que não impede que, uma vez elucidadas, possamos encontrar meios que possibilitem saná-las total ou parcialmente. O que não podemos mais, enquanto profissionais responsáveis pela saúde, é sermos coniventes com essas situações que dificultam uma prática holística do cuidado de enfermagem.

\section{EXPERIÊNCIAS SIGNIFICATIVAS DE INOVAÇÃO NA ATENÇÃO À SAÚDE}

Mostraremos duas experiências implantadas no Brasil, que viabilizam uma inovação nos sistemas de saúde, pois oferecem um atendimento holístico ou alternativo ao ser humano. 
A primeira é sobre a atuação do hospital-comunidade nas regiões norte e nordeste do Brasil, coordenado pelo Padre Velocino Zortea, da Sociedade Beneficente São Camilo, que, percebendo que a falta de informações sobre a saúde levava as pessoas dessas comunidades a adoecerem. Por isso foi iniciado um projeto de extensão do cuidar intra e extra-hospitalar, voltado à assistência domiciliar, auxiliado pela própria comunidade, através do agente de saúde local.

Esse projeto tem como objetivo central o atendimento (o cuidar) ao ser humano (pessoa, indivíduo) como parte integrante de um contexto maior (sua comunidade), levando em consideração a cultura, a história, a crença, a familia, os amigos, as limitações, as condições sócio-econômicas, o físico, o emocional e os recursos disponiveis. Os recursos especializados (hospitais) são usados somente na vigência de situações emergenciais, como acidentes e doenças agudas graves, com risco de vida.

A principal atuação é a prevenção, ou melhor, a educação básica sobre saúde, tentando evitar assim a desestabilização contínua do mundo social, cotidiano e pessoal que cada ser humano enfrenta.

A segunda experiência pertence ao Centro de Terapia Holística de Valinhos, que trabalha com uma equipe multiprofissional e com técnicas tidas como alternativas: acupuntura; florais de Bach, da Califórnia, da Austrália, do deserto, da França, da Holanda, das Filas da Gaia e das Marinhas do Pacífico; psicoterapia; fisioterapia; equilibrio energético; cromoterapia; quelação (no sentido da cura pelo toque); massagem e quiroprática. Seu objetivo central é trabalhar de forma integrada e complementar (equipe e cliente), avaliando o grau e o nivel de comprometimento e, paralelamente, conscientizar o cliente sobre o real significado de cada doença. Segundo dirigentes (Amélia e Flávio T. Verdum), já obtiveram resultados positivos com alguns tratamentos.

Essas experiências mostradas neste trabalho não pertencem especificamente à área de enfermagem, mas oferecem uma visão holística do ser humano, como também criam possibilidades novas de alternativas para à saúde no Brasil.

\section{POSSIBILIDADES DE AVANÇOS NA ENFERMAGEM}

Como observamos, os fatores podem ser externos ou internos à enfermagem. Nos externos, nós, enquanto pesquisadores, acreditamos ser dificil uma mudança, pois dependemos de conscientizações maiores (sociais) de outras categorias e do próprio sistema de saúde. Já no que diz respeito aos fatores internos, sugerimos mudanças em relação à formação e preparo do profissional enfermeiro. Para mudarmos essa realidade é importante que seja feito um trabalho complementar, com a finalidade de auxiliá-lo na edificação de sua postura, do seu papel e do seu cuidar/cuidado de enfermagem, voltados para um atendimento (sistematizado e científico) global ao cliente. Por isso propomos a aplicação das holopraxis na enfermagem. 


\section{Holopraxis intima: uma opção para a Graduação ou Pós-Graduação em Enfermagem}

Sabemos que todo organismo vivo se auto-mantém, auto-renova e autotranscende, devido à capacidade de adaptação do próprio corpo (somática) e perante o fenômeno do estresse em relação ao meio (habitat, crenças, valores, sentimento, etc.) em que se vive.

A enfermagem é uma profissão que constantemente trabalha com situações estressantes, que requerem do profissional uma estabilidade emocional maior do que a dos outros que não trabalham nessa área. Por esse motivo é importante que o profissional enfermeiro aprenda a viver, trabalhando seu "eu interior" (o self) para que mediante tais situações consiga transcender seus limites e suas inseguranças. Caso contrário, será difícil ajudar o outro a se autocuidar, pois um profissional sem autocontrole não conseguirá exercer o papel de educador ou instrutor ou terapêutico.

Para auxiliar o profissional nesse encontro consigo mesmo, propomos a utilização de recursos alternativos durante o ciclo básico da graduação em enfermagem ou depois da graduação, através de cursos de técnicas orientais de meditação e as de relacionamentos em grupos.

Acredito que, com a utilização da meditação, o enfermeiro aprenderá a "acalmar os pensamentos e emoções; entrar em contato com o 'eu' mais profundo; treinar a resistência à frustração; diminuir a ansiedade; reabastecer o físico; autoconhecimento; liberação da criatividade, além de estar apto a auxiliar o outro no autocuidado" ${ }^{18}$.

As técnicas de relacionamento em grupos poderão auxiliá-los no desenvolvimento do relacionamento interpessoal, da liderança, da solução criativa de problemas encontrados e da transformação de valores e objetivos afilados e simples em valores ricos e complexos, através da cooperação mútua e do confronto com uma situação presente.

Alguns exemplos dessas técnicas são: os "workshops" de grandes grupos (abordagem centrada-na-pessoa de Carl Rogers); os psicodramas (dramatizações de emoções fortes na presença de outros participantes, favorecendo a auto-expressão); os trabalhos manuais (auxiliam no desenvolvimento da intuição, na expressão criativa); teatralização (aplicação de textos cotidianos da vida e da enfermagem, com o objetivo de desenvolver a auto-crítica, a auto-análise e a auto-avaliação); enfim, qualquer tipo de encontro que permita um intercâmbio de idéias e que cada componente do grupo possa expressar seus valores, crenças, experiências e principalmente sua criatividade. 


\section{Holopraxis da vida cotidiana: interrelacionamento cliente / enfermeira / enfermagem}

Para que os enfermeiros possam realizar o atendimento personalizado e global, enfocando a cultura, os sentimentos, o processo saúde-doença e o autocuidado entre outros aspectos, deverão, em primeiro lugar, estar preparados como seres humanos, com estrutura suficiente para enfrentar as situações estressantes, através da holopraxis intima e, em segundo lugar, estar aptos como profissionais, através de atitudes diárias (de compaixão, bondade, alegria, amor altruísta, ética, paciência, perseverança, atenção, discernimento, prazer, ajuda, esperança e fé) nos relacionamentos enfermeiro-enfermagem, enfermeiro-enfermeiro, enfermeiro-categorias de enfermagem, enfermeirodemais profissionais de saúde, enfermeiro-sistema de saúde e principalmente enfermeiro-cliente, através da holopraxis cotidiana.

A enfermagem provavelmente conseguirá 0 entrelaçamento do cuidar/cuidado com o cliente, advindo da integração e complementação entre as categorias de enfermagem; atendimento enfocando o processo saúde-doença; novos perfil e papel da enfermeira face a outros profissionais; interdisciplinaridade; união dos métodos tradicionais com os não-tradicionais nos tratamentos terapêuticos; enfermagem domiciliar e aumento da produção científica na área da enfermagem.

\section{- Integração e complementação entre as categorias de enfermagem}

Para que haja integração e complementaridade na profissão é preciso que o atendimento de enfermagem seja dirigido à clientela e não à instituição; prática e teoria sejam usadas de forma entrelaçada e não separada; as categorias estejam cientes de que o cuidar/cuidado atenderá o processo saúde-doença e não um ou outro; cada profissional assuma seus atos com responsabilidade; a categoria como um todo reivindique condições trabalhistas: jornada de trabalho justa, piso salarial decente, redimensionamento em relação à quantidade de clientes/enfermagem, garantia institucional de condições apropriadas de estrutura física e materiais para trabalho, possibilidade de aprimoramento, entre outras; e o enfermeiro cumpra um dos seus principais papéis: o de educador, sem querer competir com outras categorias. Sabemos que esses objetivos não são fáceis de alcançar, principalmente no que se refere às instituições $e$ condições trabalhistas, e toda mudança gera resistência; mas acredito que, com o passar do tempo, os equívocos ou falhas do sistema atual serão os prováveis geradores da renovação na enfermagem e no atendimento à saúde no futuro.

\section{- Atendimento enfocando o processo saúde-doença}

A saúde e a doença devem ser vistas como antagônicas e complementares ao mesmo tempo. Necessitamos saber que cada ser humano tem o seu próprio limiar, como ser único e indivisivel, composto de corpo e mente interligados ao 
seu meio (sócio-econômico-cultural e espiritual). Portanto devemos preparar toda a equipe de enfermagem para atuar dentro dessa visão, abrindo um novo horizonte na prevenção de doenças e ajuda ao cliente para que satisfaça suas necessidades.

\section{- Novos perfil e papel da enfermeira na profissão}

Cilene $A$. C. Ide ${ }^{12}$ sugere um aprimoramento do enfermeiro, em resposta à situação atual da enfermagem: "restruturação da prática do enfermeiro no contexto das práticas assistenciais cuja complexidade passa a exigir fundamentação, integração, flexibilidade e versatilidade nas intervenções, nos padrões e ritmos de atividades". Para tanto é necessário que o enfermeiro tenha domínio intelectual da ação, preparo sobre o cuidar e coordenação deste cuidar (tanto à nível de saber como de fazer).

Os papéis do enfermeiro terão que ser interligados e complementares entre si, pois não é possível coordenar o cuidar sem ensinar o cliente e o funcionário a aplicarem esse cuidado. Acredito que, com formação intelectual, o enfermeiro não precise mais utilizar seu "cargo" para mostrar domínio numa situação. Se respeitar o cliente como ser humano (único) possuidor de direitos e deveres, possivelmente obterá um resultado favorável no cuidar/cuidado e na esperada autonomia profissional.

\section{- Interdisciplinaridade}

O sentido da interdisciplinaridade é somar esforços e interligar cliente e profissionais da saúde, para realizar um trabalho de grupo, promovendo e preservando a saúde. A interdisciplinaridade é a "interação existente entre duas ou diversas disciplinas. Esta interação pode ir desde a simples comunicação das idéias até a integração mútua dos conceitos-chave, da epistemiologia, da terminologia, da metodologia, dos processamentos dos dados e da organização da pesquisa e do ensino" (Coletânea de diversos autores, La Pluridisciplinarité. Paris, PUF; in 24).

\section{- União dos métodos tradicionais com os não-tradicionais nos tratamentos terapêuticos}

Indicamos a utilização da medicina tradicional (alopática) em casos agudos e na presença de quadros crônicos, com possibilidades de melhora no estado geral ou com chances de sobrevida; e a não-tradicional (homeopatia, acupuntura, cromoterapia, musicoterapia, medicina natural, essências de florais, os cristais e as pedras preciosas, outras) para clientes crônicos cuja doença de base não tenha cura, mas há possibilidade de estabilização do quadro, ou quando não há esperança de vida, além dos casos agudos em que os indivíduos envolvidos acreditam na terapia escolhida. Esses métodos não-tradicionais permitem um atendimento mais personalizado de cada ser humano como um todo e também porque provocam provavelmente menos danos à saúde do que os produtos alopáticos. 
Precisamos acreditar na complementaridade e não na individualização desses métodos e, como enfermeiros, devemos compreender, respeitar e conhecer a diversidade de tratamentos para que possamos orientar e ajudar nossos clientes, após a escolha de uma terapia.

\section{- Enfermagem domiciliar}

O sentido real da enfermagem domiciliar não pode ser resumido em doenças e cuidados de enfermagem, mas deverá ser voltado ao ser humano como um todo, ao processo saúde-doença e ao cuidar/cuidado preventivo, curativo, de recuperação e de reabilitação, utilizando a realidade (recursos disponíveis, cultura, valores, crenças) de cada cidadão. A proposta é uma enfermagem dirigida a uma determinada região (comunidade ou " $x$ " quarteirões) e implica na prestação do cuidar/cuidado no domicílio do cliente.

\section{- Aumento da produção científica na área de enfermagem}

Sugerimos as seguintes propostas para que se criem condições para o enfermeiro ingressar neste campo:

$\mathrm{Na}$ Graduação: introdução da disciplina de metodologia científica (no novo currículo de enfermagem isto já é uma realidade); incentivos para pesquisas em todas as disciplinas; reconhecimento das prioridades de pesquisa para o mercado de trabalho; continuidade de pesquisas já realizadas; e divulgação através de periódicos das pesquisas concluídas e em andamento.

Na Pós-Graduação: abertura de cursos de Pós em enfermagem em várias regiões do Brasil, além dos já existentes; ampliação para outras áreas (filosofia, educação, antropologia, outros) e descentralização dos enfoques até hoje pesquisados pelos enfermeiros (metodologia de enfermagem, necessidade do paciente, ensino de enfermagem, avaliação da assistência, outros); e divulgação, por meio de reformulação de acervos e do emprego de técnicas de disseminação de conhecimentos.

Próprio enfermeiro: estímulos aos colegas de trabalho; incentivo financeiro por parte das instituições empregadoras; atualização do conhecimento por meio de leituras e participações em congressos, jornadas, seminários, cursos ou outros; aquisição de pelo menos um livro por ano referente algum assunto da área de atuação; integração às entidades de classe de forma participativa; divulgação de idéias, mesmo empíricas; empenho na utilização competente das pesquisas divulgadas; revisão contínua do seu conhecimento teórico em prol de sua prática; contribuição enquanto profissional para a melhoria da imagem perante os clientes/sociedade/instituições; verificação da adequacidade, quantidade e qualidade da produção científica frente a uma realidade; criação de grupos de estudos e locais para estudo nas instituições de trabalho; e trabalho conjunto entre pesquisador e enfermeiro.

\section{Holopraxis social: interação enfermeira/enfermagem/meio social}

Para que possamos exercer um papel de renovação, transformação, integração e complementaridade com o mundo, necessitamos da utilização da holopraxis social na enfermagem, que é a maneira pela qual ela pode ser inserida num contexto maior - a sociedade, o mundo. 
Vejo essa possibilidade através da bioética, da cooperação internacional em enfermagem, da transdisciplinaridade e da participação da OMS nos sistemas de saúde.

\section{- Bioética}

A bioética surge como necessidade de salvaguardar a dignidade humana frente aos avanços tecnológicos, científicos e medicamentosos. Ela diz respeito a todos os pesquisadores, cientistas, filósofos, teólogos, sociólogos, antropólogos e profissionais da saúde que necessitam trocar informações sobre a realidade de cada ato profissional que ponha em risco a dignidade humana. $A$ enfermagem como profissão não pode estar deslocada desse contexto (inseminação artificial, bebê de proveta, armazenamento de embriões por congelamentos - os avanços na engenharia genética), pois esses assuntos produzem mudanças sociais importantes e, portanto, devem ser discutidos e elucidados por todos, para que possamos nos posicionar profissionalmente. Não podemos aceitar mais uma enfermagem alheia aos problemas sociais.

\section{Cooperação Internacional em Enfermagem}

A cooperação internacional tem no seu âmago "concepções de distintas naturezas de uma relação de troca permeada pela compreensão da determinação social dos processos econômicos, políticos e ideológicos de cada nação" ${ }^{22}$. Necessitamos de uma maior participação para troca de informações (intercâmbio cultural e técnico), através da abertura de projetos e de vagas em cursos de mestrado e doutorado em todos os continentes e de forma equânime para todos os países. Essa cooperação porém deverá respeitar e aceitar as características próprias de cada lugar e de todos que querem participar.

\section{- Transdisciplinaridade}

É algo além da interdisciplinaridade, consiste "no encontro da ciência moderna com a Tradição ${ }^{4}$ de sabedoria" 9 , transcende o enfoque disciplinar, interligando os ramos da ciência com os caminhos vivos da espiritualidade.

Basarab Nicolescu in $\mathrm{Crema}^{9}$ sugere como solução "a constituição de organismos, de centros de pesquisa transdisciplinar, reunindo especialistas de diferentes domínios e funcionando com autonomia total, em relação a todo poder econômico, político, ideológico ou administrativo", objetivando o intercâmbio de conhecimentos e idéias para constituir um mundo melhor.

Como não existe um sábio capaz de dominar todos os assuntos científicos, precisamos entrelaçar os conhecimentos dos diversos profissionais (médicos,

\footnotetext{
${ }^{4}$ A palavra Tradição, para Basarab Nicolescu, refere-se "ao conjunto das doutrinas e práticas religiosas ou morais, transmitidas de século a século, originalmente pela palavra ou exemplo, ou também, conjunto de informações mais ou menos legendárias, relativas ao passado, transmitidas oralmente de geração em geração. (...) Ela diz respeito à transmissão de um conjunto de conhecimentos sobre a evolução espiritual do homem, sua posição nos diferentes mundos, sua relação com diferentes cosmos" 9 .
} 
filósofos, artistas, professores, poetas, enfermeiros, místicos, teólogos e outros) com a sabedoria dos seres humanos, tendo como meta a busca da felicidade e harmonia mundial.

\section{- Participação da OMS}

Acreditamos que essa participação seja facilitadora de encontros entre enfermeiros e demais categorias profissionais da saúde. Essa proposta com certeza reduziria o distanciamento dos países, favoreceria o intercâmbio cultural e profissional e auxiliaria a própria OMS na percepção da realidade em que vivem esses países.

\section{CONCLUSÃO}

As teorias Transcultural, Transpessoal, de Autocuidado e de Sistemas Abertos permitem um cuidar/cuidado eficaz de enfermagem ao cliente como um todo (bio-psico-sócio-econômico-espiritual e cultural). Porém, devido às dificuldades existentes no sistema de saúde e na profissão, esse atendimento torna-se restrito e deficitário.

Acreditamos, portanto, que superaremos essas dificuldades através da interligação das holopraxis intima, cotidiana e social na enfermagem.

$\mathrm{Na}$ holopraxis íntima, o enfermeiro encontrará meios (dentro da Graduação ou da Pós-Graduação) para se estruturar através do autoconhecimento e autotranscendência.

$\mathrm{Na}$ holopraxis cotidiana, compreenderá o sentido das tradições, valores, crenças e os sentimentos de bondade, carinho, alegria e amor, através do interrelacionamento com o cliente e colegas de trabalho.

$\mathrm{Na}$ holopraxis social, entenderá melhor a enfermagem, reconhecendo seu valor como profissão e a necessidade de sua interação com o meio (intercâmbio cultural).

As holopraxis podem até não ser a solução definitiva para as dificuldades atualmente encontradas, mas, com certeza, proporcionam meios para amenizálas. 


\section{REFERÊNCIAS BIBLIOGRÁFICAS}

1. BOEHS, A . E. e PATRICIO, Z. M. O que é este "cuidar/cuidado"? - Uma abordagem inicial. São Paulo: Revista da Escola de Enfermagem da USP. São Paulo, v. 24, n. 1, p. 111-6, abril, 1990.

2. BRANDÃO, D. M. e CREMA, R. O novo paradigma holístico. Ciência, filosofia, arte e mística. São Paulo: Summus, 1991.

3. Visão holística em psicologia e educação. São Paulo: Summus, 1991.

4. CAPRA, F. O tao da física. São Paulo: Cultrix, 1991.

5. O ponto de mutação. São Paulo: Cultrix, 1992.

6. CARVALHO, E. C. e PELA, N. T. R. Modelo de análise do conhecimento na enfermagem. Revista da Escola de Enfermagem da USP. São Paulo, v. 27, n. 3, p. 116-21, set./dez., 1992.

7. CASTILHO, V. A implementação de um programa de pesquisa em um serviço de enfermagem. Revista da Escola de Enfermagem da USP. São Paulo, v. 27, n. 1, p. 197-8, abril, 1993.

8. COREN. Código de ética dos profissionais de enfermagem. São Paulo, 1993.

9. CREMA, R. Introdução à visão holística. São Paulo: Summus, 1989.

10. DALLA COSTA, I. A. Holopraxis na enfermagem: dificuldades, experiências e possibilidades. Piracicaba: Pós-Graduação, 1995.

11. GEORGE, J. B. et al.. Teorias de enfermagem. Porto Alegre: Artes Médicas, 1993.

12. IDE, C. A . C. O ser "trabalhador de enfermagem" e o ser "doente" : Considerações sobre o desempenho de papéis sociais. Revista da Escola de Enfermagem da USP. São Paulo, v. 25, n. 1, p. 103-12, 1991.

13. Enfermagem: uma intenção, uma opção, uma prática no tempo de nossas vidas. Revista da Escola de Enfermagem da USP. São Paulo, v. 27, n. 1, p. 5-8, abril, 1993.

14. IGNATTI, C. Uma proposta de prática de enfermagem holística.

Piracicaba: Pós-Graduação, 1992. 
15. LANDMANN, J. Evitando a saúde \& promovendo a doença. 3. ed. - O sistema de saúde no Brasil. Rio de Janeiro: Achiamé, 1982.

16. LONGATO, A . Os hospitais voltados para a sua comunidade. Revista Hospital-Administração e Saúde. São Paulo, v. 13, n. 2, p. 98-100, abr./jun., 1989.

17. NASCIMENTO, E. M. F. A enfermagem profissional moderna brasileira está doente. R. Bras. Enferm. Brasilia, v. 44, n. 2,3, p. 21-5, abr./set., 1991.

18. OSHO. Meditação. A arte do êxtase. São Paulo: Cultrix/Pensamento. Organizado por Ma Satya Bharti, 1991.

19. PEREIRA, R. C. J. Promir.ão da saúde e prevenção de doenças: responsabilidade individual ou responsabilidade social. Revista da Escola de Enfermagem da USP. São Paulo, v. 26, n. 3, p. 345-350, dez., 1992.

20. PESSINI, L. Bioética: um grito pela dignidade humana e qualidade de vida. Revista Hospital - Administração e Saúde. São Paulo, v. 18, n. 5, p. 295, set./out. 1994.

21. SILVA, C. M. et al. Pesquisa em enfermagem: importância e sua evolução no Brasil. Revista Acta Paulista de Enfermagem. São Paulo, v. 41, n. 1, p. 34-8, março, 1991.

22. SOUZA, A. M. A. e CHOMPRÉ, R. R. .Cooperação Internacional em enfermagem. R. Bras. Enferm. Brasilia, v. 41, n. 3,4, p. 252-4, jul./dez., 1988.

23. TAVARES, C. Iniciação à visão holística. Rio de Janeiro: Record, Coleção Iniciação, 1993.

24. WEIL, P. Nova linguagem holística. Rio de Janeiro: Co-edição Espaço e Tempo/CEPA, 1987.

25. ZOHAR, D. O ser quântico. Uma visão revolucionária da natureza humana e da consciência, baseada na nova física. 4. ed. São Paulo: Best Seller, 1990. 